Gerontologia 1972;18:395-396

\title{
Index rerum Vol. 18
}

\section{Acridinorange 113}

ACTH and nucleoprotein structure 113 Advances in gerontological research (B) Age pigment 1, 157, 217 Amyloidosis 321 Antibody formation 63, 77 Autoantibody 285 Autoimmunity 185, 285 Autoradiography 147

Bacterial endotoxin and leukocytes 63

Blood on immunology 200

Body temperature 363

Bordetella pertussis adjuvant 63, 77

Bovine Achilles tendon 22

Calorimetry and tendron 22 Cancer basic protein 185 Cartilaginous intervertebral disc structure 157 Cellular defects 305 Cerebral areas 1

\section{- $\quad$ circulation 14}

Chromatography of collagen 169 Chronic respiratory disease 267 Collagen crosslinks 28, 169

- $\quad$ polymers 169

Compensatory strategy 193

Cortex and lipofuscin 1, 217

Crosslinks in collagen 28, 169

Cytophotometry 113, 122, 147

DNA content in gland cells 131, 147

59 Encephalitogenic factor 185 Enzyme patterns in mouse 36 Exothermic transition 22

Fibrocytes and intervertebral disc 157

Glandular cells 131, 147 Glial cells and lipofuscin 1, 217 Glomerulonephritis 200 Glucosamine incorporation 96 Glucose assimilation 176 Granulation tissue 96 Guinea pig liver nuclei 122

Hemolysin 63

Herniation 157

Histochemistry, liver and lung 36

Histology and gland cells 131, 147

Homeotherms 363

Human cerebral circulation 14

intervertebral disc 157

learning 193

lymphocytes 185 Hyperglycemia 176 Hypothermia 363

Immune deficiency 305

- $\quad$ response 77, 305

Immunocompetence 285

396

Index rerum Vol. 18 
Immunoepidemiology 285 Immunoglobulin level 267 Immunologic equilibrium 247 Immunology 63, 77, 176, 185, 200, 247

267, 285, 305, 321, 363 Immunopathology 285, 321 Insulinemia 176 Intervertebral disc 157

Kidney and immunology 200

Learning 193 Leukocytosis 63 Lifespan 363 Lipofuscin 1, 217 Liver, enzyme pattern 36

- $\quad$ nucleoprotein 113,122

Lymphocyte sensitization 185

Lysinoaldehyde 28

Lysosomal enzymes 96

Marihuana derivatives 363 Mouse, antibody formation 63, 77

enzyme patterns 36

glomerulonephritis 200

leukocytes 63

Neurons and lipofuscin 1,217 Nucleoprotein 113, 122

Pertussis vaccine and leukocytes 63 Phenanthrenquinone 113

Plethysmography 14 Poikilotherms 363 Polyploidisation 147 Prediction 193 Primary aging 247

Prolapsus 157 Proline incorporation 96

Radioimmunological insulin test 176 Rat cortical areas 1

gland cells 131,147

liver nuclei 113

insulinemia 176

lysosomal enzymes 96

tendon collagen 28, 169 Repeating cycle 193 Research in gerontology (B) 59 Respiratory disease 267

Sakaguchi reaction 122 Secondary ageing 247 Serum immunoglobulin level 267 Sex and gland cells 131, 147 Sheep erythrocytes 77 Solubility of collagen 169

Tendon collagen 28, 169

- $\quad$ exothermic transition 22

Teasimatry and collagen fibres 28

Tuberculosis 321

Urine and immunology 200 